pattern. Ventricular ectopy is non-specific, but is associated with both cardiomyopathic and channelopathic processes in a significant minority. ST segment depression, however, is unhelpful and should be viewed in the context of the patient's cardiovascular risk profile.

\section{LOW-DOSE SODIUM NITRITE RELIEVES MYOCARDIAL ISCHAEMIA IN PATIENTS WITH CORONARY ARTERY DISEASE: A TARGETED NO-DONOR EFFECT}

doi:10.1136/heartjnl-2011-300198.51

${ }^{1} \mathrm{~T}$ E Ingram, ${ }^{2} \mathrm{R}$ A Bleasdale, ${ }^{2} \mathrm{C}$ Templeton, ${ }^{2} \mathrm{C}$ Williams, ${ }^{1} \mathrm{~A}$ Margulescu, ${ }^{1} \mathrm{~A}$ G Fraser, ${ }^{1} \mathrm{P}$ E James. ${ }^{1}$ Cardiff University, Cardiff, UK; ${ }^{2}$ Royal Glamorgan Hospital, Llantrisant, UK

Introduction Sodium nitrite $\left(\mathrm{NaNO}_{2}\right)$ became a popular means of treating angina in the 19th century, as its stable chemical structure allowed for cheap preparation and easy storage. However, the effects were slow and unpredictable and so it fell out of favour as more potent and faster-acting agents became available, (eg, organic nitrates). Recent in vitro evidence shows that nitrite $\left(\mathrm{NO}_{2}^{-}\right)$exhibits an enhanced vasodilator effect in hypoxia; an environmental modification which encourages its reduction to nitric oxide (NO). Therefore $\mathrm{NaNO}_{2}$ could potentially be an anti-ischaemic agent at much lower doses than those used historically, and be without the adverse side effects associated with organic nitrates (eg, systemic hypotension and tachyphylaxis).

Method A double-blind, placebo-controlled, cross-over study was performed in 10 subjects with proven myocardial ischaemia documented by exercise tolerance testing and coronary angiography. Two dobutamine stress echocardiography (DSE) studies were performed on each subject: one with $0.9 \%$ saline and one with $\mathrm{NaNO}_{2}$, $1.5 \mu \mathrm{mol} / \mathrm{min}$ for $20 \mathrm{~min}$. This dose of $\mathrm{NaNO}_{2}$ has previously been shown to be inert in normoxia but to vasodilate hypoxic tissue. Myocardial ischaemia was identified by the peak systolic velocity (PSV) response during DSE in a six basal-wall segment model of the left ventricle. Using placebo study data-set, walls were classified into tertiles: the lowest tertile of responders of PSV to an increase in heart rate $(\Delta \mathrm{HR})$ labelled ischaemia $(\mathrm{n}=18)$ and the upper tertile control $(n=18)$. Data was divided into four groups according to the study-infusion received and the myocardial-wall examined: saline/ ischaemia, $\mathrm{NO}_{2}^{-}$/ischaemia, saline/control and $\mathrm{NO}_{2}^{-}$/control.

Results Data from each stage of each DSE was plotted on a scatter plot graph with change in $(\Delta \mathrm{HR})$ on the $\mathrm{x}$-axis and corresponding change in PSV $(\triangle \mathrm{PSV})$ on the $y$-axis (increase in both values compared to baseline), see Abstract 51 figures 1 and 2. Linear regression analysis of the saline/ischaemia group was lower than the $\mathrm{NO}_{2}{ }^{-}$/ischaemia group, with no overlap in their $95 \% \mathrm{CI}$, see Abstract 51 figure 1. In addition, the linear regression gradient of the $\mathrm{NO}_{2}^{-}$/ ischaemia group was similar to the saline/control and the $\mathrm{NO}_{2}^{-}$/control gradient, see Abstract 51 figure 2. The peak-dose dobutamine values

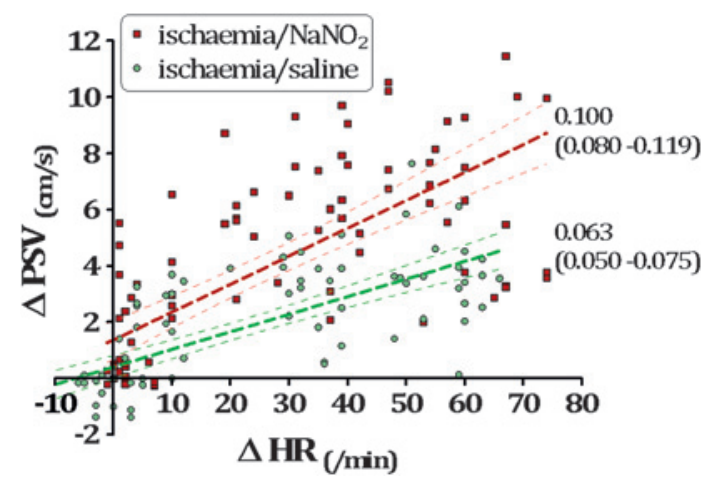

Abstract 51 Figure 1 of $\Delta \mathrm{PSV} / \Delta \mathrm{HR}$ were different in the saline/ischaemia group compared to the three other groups (ie, saline/ischaemia $=3.7 \pm 0.6 \mathrm{~cm} / \mathrm{s} / \mathrm{s}$, $\mathrm{NO}_{2}{ }^{-} /$ischaemia $=8.2 \pm 1.0 \mathrm{~cm} / \mathrm{s} / \mathrm{s}$, saline $/$ control $=10.5 \pm 1.1 \mathrm{~cm} / \mathrm{s} / \mathrm{s}$, $\mathrm{NO}_{2}{ }^{-}$/control $=8.4 \pm 0.7 \mathrm{~cm} / \mathrm{s} / \mathrm{s} ; \mathrm{p}<0.01$, repeated-measures ANOVA with Bonferroni post-test). No difference was present between the three other groups.

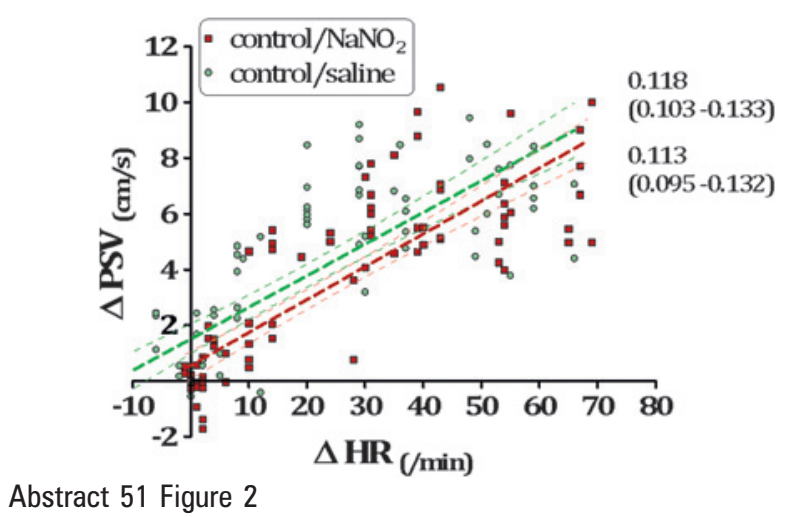

Conclusions Low-dose $\mathrm{NaNO}_{2}$ delivers a therapeutic effect to ischaemic myocardial tissue in the absence of a vasodilator effect on normoxic tissue. This is the first study in patients to demonstrate a targeted vasodilator effect of $\mathrm{NO}_{2}^{-}$to tissues in need only.

\section{BRAIN NATRIURETIC PEPTIDE PREDICTS ALL CAUSE MORTALITY IN PATIENTS WITH TYPE 2 DIABETES AND NORMAL EJECTION FRACTIONS}

doi:10.1136/heartjnl-2011-300198.52

${ }^{1} \mathrm{~B}$ R Szwejkowski, ${ }^{1} \mathrm{D}$ H J Elder, ${ }^{2} \mathrm{~A}$ Dawson, ${ }^{1} \mathrm{~A}$ D Struthers. ${ }^{1}$ University of Dundee, Dundee, UK; ${ }^{2}$ Department of Cardiology, NHS Tayside, Dundee, UK

Introduction The use of brain naturetic peptide (BNP) to predict outcome in patients with normal ejection fractions (EF) and type 2 diabetes (T2DM) is understudied. Only three previous studies have specifically addressed the question as to whether BNP adds prognostic information in T2DM. There appears to be a link between survival and BNP in T2DM, however these studies included small numbers of patients and did not fully exclude left ventricular systolic dysfunction (LVSD). We therefore studied the 5-year survival in a cohort of 500 T2DM patients prospectively phenotyped with echocardiography.

Methods 500 patients with T2DM where studied with echocardiography between April 2002 and October 2003. Patients were recruited from the diabetes clinics at Ninewells Hospital, Dundee. Transthoracic echocardiography was performed by one trained operator and left ventricular (LV) assessment was performed using modified biplane Simpson's method over three cycles. We excluded individuals with EF of $<55 \%$. Follow-up data was linked via the Health Informatics Centre (HIC), to mortality data, laboratory test data, hospitalisation, and prescribing via the community health index (CHI) number. Cox proportional hazards model was used to examine the effects of BNP (bedside stick measurement) measure on all-cause mortality using age, sex, smoking status, hypertension, IHD, duration of diabetes, and diabetic drug prescription as co-variants. Outcome was all cause mortality.

Results In total we followed 316 patients over 8 years. 56 patients died over this time. After adjusting for confounding factors we have shown that for every 10-unit increase in BNP there is a $6 \%$ increased risk of death. HR 1.06 (95\% CI 1.02 to 1.10$)(p=<0.01)$.

Conclusions In patients with normal EF, BNP is an independent predictor of death in a cohort of T2DM patients. Although more research is needed, BNP may become an important tool in risk stratifying T2DM patients in the future. 